\title{
La mediación artística como estrategia de inclusión social con juventud migrada
}

\author{
Javiera-Alejandra Tarragó-Diez ${ }^{1}$ \\ Artículo de estudios y tendencias. Recibido: 30/10/2020. Aceptado: 27/11/2020. Publicación avanzada: 17/12/2020. Publicado: 04/01/2021.
}

Resumen

INTRODUCCIÓN. Este artículo da cuenta de una investigación acción llevada a cabo en un taller de teatro social con juventud migrada en Barcelona. Se presenta al colectivo en cuestión, así como la situación de exclusión social en la que se encuentran; se sitúa el contexto de la intervención, el problema de investigación y los objetivos.

MÉTODO. La investigación es de carácter inductivo y la metodología elegida es una fusión de investigación evaluativa con un enfoque participativo y una investigación acción. El diseño de la investigación se presenta en tres fases: diagnóstico, acción y valoración.

RESULTADOS. Se da cuenta de las necesidades de inclusión social de la juventud, se propone un diseño de taller de teatro social adaptado a esta realidad y se valora la pertinencia de la mediación artística como herramienta de inclusión social.

CONCLUSIONES. Se reflexiona sobre los límites y la posibilidad de la mediación artística, sobre las condiciones necesarias para llevar a cabo un taller artístico en este contexto particular y se recopilan algunas claves metodológicas para orientar a otros y otras profesionales interesadas en la labor socioeducativa a través del arte.

\section{Palabras clave}

Exclusión social; Migración; Adolescentes; Educación ciudadana; Educación artística.

\section{Datos de la autora}

1 Universitat de Barcelona, España. Actriz, máster en Intervenciones Sociales y Educativas. Contacto para la correspondencia: javiera.tarrago@gmail.com

\section{Referencia recomendada}

Tarragó-Diez, J. A. (2021). La mediación artística como estrategia de inclusión social con juventud migrada. REIRE Revista d'Innovació $i$ Recerca en Educació, 14(1), 1-18. https://doi.org/10.1344/reire2021.14.132690

(C) 2021 La autora. Este artículo es de acceso abierto sujeto a la licencia Reconocimiento 4.0 Internacional de Creative Commons, la cual permite utilizar, distribuir y reproducir por cualquier medio sin restricciones siempre que se cite adecuadamente la obra original. Para ver una copia de esta licencia, visite https://creativecommons.org/licenses/by/4.0/ 


\section{Títol (català)}

La mediació artística com a estratègia d'inclusió social amb joventut migrada

\section{Resum}

INTRODUCCIÓ. Aquest article dona compte d'una recerca acció duta a terme en un taller de teatre social amb joventut migrada a Barcelona. Es presenta el col·lectiu en qüestió, així com la situació d’exclusió social en la qual es troben, i se situa el context de la intervenció, el problema de recerca i els objectius.

MÈTODE. La recerca és de caràcter inductiu i la metodologia triada és una fusió de recerca avaluativa amb un enfocament participatiu i una recerca acció. El disseny de la recerca es presenta en tres fases: diagnòstic, acció i valoració.

RESULTATS. S'expliquen les necessitats d'inclusió social del grup de joves, es proposa un disseny de taller de teatre social adaptat a aquesta realitat i es valora la pertinència de la mediació artística com a eina d'inclusió social.

CONCLUSIONS. Es reflexiona sobre els límits i la possibilitat de la mediació artística; sobre les condicions necessàries per dur a terme un taller artístic en aquest context particular i es recopilen algunes claus metodològiques per orientar altres professionals amb interès per la tasca socioeducativa a través de l'art.

\section{Paraules clau}

Exclusió social; Migració; Adolescents; Educació ciutadana; Educació artística.

\section{Title (English)}

Artistic mediation as a social inclusion strategy for young immigrants

\section{Abstract}

INTRODUCTION. This article describes an action research programme carried out in a social theatre workshop with young immigrants in Barcelona. We describe the group itself and the situation of social exclusion in which they find themselves, and outline the context of the intervention and the nature and the objectives of the research.

METHOD. In this inductive study, the methodology chosen is a fusion of evaluative research, a participatory approach, and action research. The study has three phases: diagnosis, action and assessment.

RESULTS. This study highlights the need for social inclusion among young immigrants, proposes a design of social theatre workshop adapted to this situation, and assesses the relevance of artistic mediation as a tool for social inclusion.

CONCLUSIONS. The author reflects on the limits and possibility of artistic mediation, discusses the conditions needed to run an artistic workshop in this particular context, and offers some methodological guidelines for other professionals interested in the application of art in socio-educational contexts.

\section{Keywords}

Social exclusion; Migration; Teenagers; Citizenship education; Art education. 


\section{Introducción}

El colectivo "juventud migrada" se refiere en este estudio a aquellas personas entre 16 y 34 años que residen en Cataluña, que tienen nacionalidad extranjera o que han nacido en el extranjero, y que han migrado ya sea por cuenta propia o como parte de un proyecto familiar. Se trata de un colectivo muy diverso, con condiciones de vida y contextos muy diferentes entre sí. Sin embargo, pese a las distinciones de cada caso particular, frecuentemente son personas con un alto grado de vulnerabilidad y de riesgo social, en el sentido de que en ellas se intersectan diferentes ejes de desigualdad que bañan de injusticia y discriminación sus historias vitales. En las últimas décadas se ha producido un aumento continuo de la juventud migrada en Cataluña. Entre tres y cuatro de cada diez jóvenes en Cataluña son de origen extranjero (Serracant, 2013). De acuerdo con Gimeno (2014), este es "un fenómeno estructural y crónico vinculado al malestar, a la pobreza y a la exclusión de estos jóvenes en el sistema socioeconómico y cultural dominante" (p. 34).

Subirats et al. (2009) reconoce tres ejes básicos de inclusión social de cualquier persona, colectivo o territorio. En primer lugar, se postula que la inclusión social pasa por el acceso a la ciudadanía y a los derechos que se desprenden de ella, así como la participación efectiva en la esfera política. En segundo lugar, se mencionan los vínculos y las conexiones sociales como condición básica de la inclusión de toda persona o grupo social, ya sean de carácter afectivo, familiar, vecinal, comunitario o de otro tipo. En tercer lugar, el espacio de producción económica y del mercado de trabajo. Teniendo en cuenta estos ejes, se puede deducir que existen colectivos a los cuales les resulta extremadamente difícil transitar desde el polo de la exclusión hacia el polo de la inclusión social. La población migrada es un ejemplo de esto, con una Ley de Extranjería encima que les imposibilita la adquisición de derechos de ciudadanía -y con ello la incorporación al mercado de trabajo- y con limitados vínculos y conexiones afectivas en el territorio de acogida, "recuperar un sentido integral de la humanidad, de la condición de persona y de ciudadano" (Subirats, 2004, p. 139) parece ser casi una utopía. Por su parte, Castel (1995) da a entender que la "marginalidad y la desafiliación" (s. p.) que se vive en la zona de exclusión podría ser evitada si se aborda cuando aún se está en la zona de vulnerabilidad, y propone como estrategia de intervención la formación.

En esta investigación propongo como estrategia de intervención la mediación artística. Se trata de un cruce de caminos entre la educación social, la educación artística y la arteterapia (Moreno, 2016), para intentar concentrar a las diferentes disciplinas que desde distintos frentes y con diversas denominaciones buscan lo mismo: generar cambios individuales y colectivos por medio de las herramientas artísticas. Moreno (2016) la define como "la intervención socioeducativa a través de proyectos artísticos y culturales con personas y grupos en situación de exclusión social, con comunidades vulnerables y para la cultura de paz" (p. 16).

La investigación que recoge este artículo se lleva a cabo en un taller de teatro social dictado por la autora, que forma parte de un programa socioeducativo de la ciudad de Barcelona y que atiende precisamente al colectivo en cuestión. El De Deu a Una nace el año 2013, impulsado por el Ayuntamiento de Barcelona, con la intención de ofrecer información, asesoramiento y acompañamiento a jóvenes entre 16 y 25 años que no estudian ni trabajan, a través de un conjunto de acciones con el objetivo de colaborar en su proceso de orientación o de inserción laboral. Si bien el programa no está dirigido explícitamente a jóvenes de origen extranjero, en la práctica la mayoría de usuarios lo son. El servicio funciona como un programa de entrada y salida, esto quiere decir que los y las jóvenes participan hasta que deciden marchar para continuar con a una vía formativa o laboral. Los encuentros se realizan en el Casal Les Basses de Nou Barris y en el Centre Cívic de Sant Martí, de lunes a viernes, de 10 de la mañana a 1 de la tarde. Las actividades varían entre talleres fijos -cocina, deporte y teatro social-y salidas o actividades variadas. 
El taller de teatro social forma parte de la plantilla fija de actividades que se realizan de manera semanal en el programa. Sin embargo, las profesionales a cargo de la coordinación de este, en vistas del fracaso que ha tenido este taller en los últimos años, han perdido la confianza en la herramienta artística como estrategia pertinente a utilizar con este colectivo en particular, porque dudan de la voluntad de participación y exposición de los y las adolescentes. Por esta razón, durante los siete años de antigüedad del programa, ha habido una gran rotación de talleristas de teatro social, que no han conseguido adaptarse a la complejidad de este contexto. Algunos años incluso se ha reemplazado el taller por otra actividad fija. Ante esta realidad, el problema de investigación en el cual se centra este estudio, es comprender de qué manera se puede adaptar un taller de teatro social a este contexto particular, para que sus objetivos, estructura, contenidos y actividades, por una parte sean bien recibidas por parte de los y las jóvenes que forman parte del programa -representando aprendizajes significativos para su desarrollo personal e inclusión social- $y$, por otra parte, recupere la confianza por parte de las profesionales a cargo de la coordinación del programa.

De esta manera, los objetivos de la investigación son conocer el contexto de la intervención para recoger las necesidades de inclusión social de la juventud participante y desde aquí desarrollar una propuesta de mejora para el taller de teatro social. Y además valorar sus resultados en relación con la pertinencia de la mediación artística como vehículo de inclusión social con el colectivo de jóvenes del De Deu a Una.

\section{Método}

Esta investigación es fruto de un proceso prioritariamente inductivo, cuya base y sustento es la práctica, es decir, la acción que se desarrolla a lo largo de las diferentes operaciones de un proceso de intervención social y educativo. Por lo tanto, se busca una metodología que se adapte a las necesidades y a las características de la situación de intervención y que permita evaluar su impacto. Inicialmente, se opta por investigación evaluativa con un enfoque participativo, en vistas de que lo que se pretende es evaluar participativamente el taller de teatro social para proponer mejoras. Pero a medida que se lleva a cabo, surge la necesidad de identificarlo también como una investigación acción, porque presenta cada vez más rasgos en común con esta última metodología; una estructura de diagnóstico-acción-reflexión y un conocimiento generado a partir de la intervención. Como existen tantas zonas de contacto entre ambos enfoques, se opta por no etiquetar esta investigación como la una o la otra, sino más bien como una combinación de ambas metodologías, prestando más atención a aquellas características que las unen que a aquellas que las distinguen.

La investigación se compone de tres fases fundamentales, que corresponden a las diferentes fases del proceso de intervención. A pesar de que en la teoría las fases se presentan de manera separada, tanto en la información que apuntan a recoger como en la temporalidad, en la realidad estas se encuentran interconectadas.

La primera fase de esta investigación se lleva a cabo entre el 14 de octubre y el 16 de diciembre de 2019, cada lunes, durante tres horas, en el taller de teatro social De Deu a Una, dinamizado por la autora de esta publicación. Durante esta fase se realiza la aproximación al contexto, se definen las líneas y objetivos de la investigación, se inicia el proceso de recogida y registro de datos y se realiza un diagnóstico participativo de necesidades de inclusión social (ver más detalles en la Tabla 1). 
Tabla 1

Diseño de la fase I de la investigación

\begin{tabular}{|c|c|c|c|c|}
\hline $\begin{array}{c}\text { Dimensiones de } \\
\text { contenido }\end{array}$ & $\begin{array}{l}\text { ¿Cómo obtenemos } \\
\text { la información? }\end{array}$ & $\begin{array}{c}\text { ¿De quién o de } \\
\text { dónde obtenemos } \\
\text { los datos? }\end{array}$ & $\begin{array}{c}\text { Juicios a emitir } \\
\text { desde la evaluación }\end{array}$ & $\begin{array}{c}\text { Toma de decisiones } \\
\text { derivada }\end{array}$ \\
\hline $\begin{array}{l}\text { Percepción sobre las } \\
\text { necesidades, los } \\
\text { espacios de } \\
\text { participación, los } \\
\text { factores de riesgo, } \\
\text { las oportunidades } \\
\text { y los factores de } \\
\text { protección, en } \\
\text { relación con la } \\
\text { inclusión social de } \\
\text { la juventud } \\
\text { migrada del De } \\
\text { Deu a Una. } \\
\text { (Necesidades } \\
\text { sentidas) }\end{array}$ & $\begin{array}{l}\text { - Observación } \\
\text { participante } \\
\text { - Diario de campo } \\
\text { - Taller de } \\
\text { recolección de } \\
\text { necesidades }\end{array}$ & $\begin{array}{l}\text { - Tallerista de teatro } \\
\text { social } \\
\text { - Jóvenes que } \\
\text { participan del } \\
\text { taller de teatro } \\
\text { social, Nou Barris }\end{array}$ & $\begin{array}{l}\text { ¿Cuáles son las } \\
\text { necesidades, los } \\
\text { espacios de } \\
\text { participación, los } \\
\text { factores de riesgo, } \\
\text { las oportunidades } \\
\text { y los factores de } \\
\text { protección de la } \\
\text { juventud migrada } \\
\text { en relación con su } \\
\text { inclusión social? }\end{array}$ & \multirow[t]{3}{*}{$\begin{array}{l}\text { A partir de la } \\
\text { evaluación de } \\
\text { necesidades; } \\
\text { ¿Cómo debe } \\
\text { adaptarse el taller } \\
\text { de teatro social } \\
\text { para que en este } \\
\text { los y las jóvenes } \\
\text { puedan expresar } \\
\text { sus necesidades e } \\
\text { inquietudes, y } \\
\text { desarrollar } \\
\text { competencias que } \\
\text { favorezcan su } \\
\text { inclusión social? }\end{array}$} \\
\hline $\begin{array}{l}\text { Necesidades, } \\
\text { espacios de } \\
\text { participación, } \\
\text { factores de riesgo, } \\
\text { oportunidades y } \\
\text { factores de } \\
\text { protección, en } \\
\text { relación con la } \\
\text { inclusión social } \\
\text { expresadas por } \\
\text { otros } \\
\text { profesionales del } \\
\text { De Deu a Una. } \\
\text { (Necesidades } \\
\text { expresadas) }\end{array}$ & $\begin{array}{l}\text { - Entrevista grupal } \\
\text { - Observación } \\
\text { participante } \\
\text { - Diario de campo } \\
\text { - Análisis } \\
\text { documental. } \\
\text { (documentos } \\
\text { oficiales: memorias } \\
\text { del programa) }\end{array}$ & $\begin{array}{l}\text { - Coordinación del } \\
\text { programa } \\
\text { - Otros talleristas } \\
\text { - Tallerista de teatro } \\
\text { social } \\
\text { - Memoria del } \\
\text { programa De Deu } \\
\text { a Una }\end{array}$ & $\begin{array}{l}\text { ¿Cuáles son las } \\
\text { necesidades, los } \\
\text { espacios de } \\
\text { participación, los } \\
\text { factores de riesgo, } \\
\text { las oportunidades } \\
\text { y los factores de } \\
\text { protección de la } \\
\text { juventud migrada } \\
\text { en relación con su } \\
\text { inclusión social } \\
\text { según los otros } \\
\text { profesionales del } \\
\text { programa? }\end{array}$ & \\
\hline $\begin{array}{l}\text { Necesidades, } \\
\text { espacios de } \\
\text { participación, } \\
\text { factores de riesgo, } \\
\text { oportunidades y } \\
\text { factores de } \\
\text { protección, en } \\
\text { relación con la } \\
\text { inclusión social } \\
\text { constatadas por la } \\
\text { literatura. } \\
\text { (Necesidad } \\
\text { normativa) }\end{array}$ & $\begin{array}{l}\text { - Búsqueda } \\
\text { bibliográfica }\end{array}$ & $\begin{array}{l}\text { - Fuentes } \\
\text { bibliográficas } \\
\text { selectas }\end{array}$ & $\begin{array}{l}\text { ¿Cuáles son las } \\
\text { necesidades, los } \\
\text { espacios de } \\
\text { participación, los } \\
\text { factores de riesgo, } \\
\text { las oportunidades, } \\
\text { los factores de } \\
\text { protección de la } \\
\text { juventud migrada, } \\
\text { en relación con su } \\
\text { inclusión social, } \\
\text { según la literatura } \\
\text { disponible? }\end{array}$ & \\
\hline
\end{tabular}

Fuente: Elaboración propia. 
En la segunda fase de esta investigación se pone en práctica la intervención y tiene por finalidad diseñar, implementar y monitorear un taller de teatro social hecho a medida del grupo de jóvenes, considerando sus intereses y necesidades de inclusión social detectadas durante la fase anterior. De esta manera, se plantea un taller de 13 sesiones de tres horas de duración que, a través de una metodología de trabajo inspirada en el Teatro de las Oprimidas de Augusto Boal (1980), pretende favorecer el desarrollo de valores ciudadanos y de habilidades socioafectivas, como estrategia de inclusión social (ver Tabla 2 para más detalles).

En esta etapa de la investigación se realiza una sinergia con una estudiante del máster de Mediación Artística de la Universitat de Barcelona, también interesada en investigar en torno al teatro de las oprimidas con personas migradas. De esta manera, Elena Donoso participa del taller como estudiante en prácticas, en primera instancia como observadora externa y colaborando en la recogida y registro de información.

\section{Tabla 2}

Diseño de la fase ll de la investigación

\begin{tabular}{|c|c|c|c|c|}
\hline $\begin{array}{l}\text { Dimensiones de } \\
\text { contenido }\end{array}$ & $\begin{array}{l}\text { ¿Cómo obtenemos } \\
\text { la información? }\end{array}$ & $\begin{array}{l}\text { ¿De quién o de } \\
\text { dónde obtenemos } \\
\text { los datos? }\end{array}$ & $\begin{array}{c}\text { Juicios a emitir } \\
\text { desde la evaluación }\end{array}$ & $\begin{array}{c}\text { Toma de decisiones } \\
\text { derivada }\end{array}$ \\
\hline $\begin{array}{l}\text { Planificación del } \\
\text { taller }\end{array}$ & $\begin{array}{l}\text { - Búsqueda } \\
\text { bibliográfica }\end{array}$ & $\begin{array}{l}\text { - Fuentes } \\
\text { bibliográficas } \\
\text { selectas }\end{array}$ & $\begin{array}{l}\text { ¿Qué tipo de } \\
\text { actividades se } \\
\text { pueden ajustar a } \\
\text { las necesidades e } \\
\text { intereses de las } \\
\text { personas } \\
\text { destinatarias del } \\
\text { taller? }\end{array}$ & $\begin{array}{l}\text { Cronograma y } \\
\text { planificación de la } \\
\text { intervención }\end{array}$ \\
\hline $\begin{array}{l}\text { Implementación del } \\
\text { taller }\end{array}$ & $\begin{array}{l}\text { - Observación } \\
\text { participante } \\
\text { - Lista de asistencia } \\
\text { - Cronograma } \\
\text { - Material artístico }\end{array}$ & $\begin{array}{l}\text { - Tallerista de teatro } \\
\text { social } \\
\text { - Observadora } \\
\text { externa } \\
\text { - Coordinación del } \\
\text { programa } \\
\text { - Jóvenes } \\
\text { - Videos de registro } \\
\text { de las } \\
\text { improvisaciones }\end{array}$ & $\begin{array}{l}\text { ¿Se mantiene el } \\
\text { grupo para el cual } \\
\text { fue diseñado el } \\
\text { taller? } \\
\text { ¿Se ajusta al } \\
\text { calendario } \\
\text { previsto? } \\
\text { ¿Se ajustan los } \\
\text { recursos a las } \\
\text { necesidades del } \\
\text { taller? } \\
\text { ¿Se consigue } \\
\text { estructurar un } \\
\text { proyecto creativo } \\
\text { colaborativo? }\end{array}$ & $\begin{array}{l}\text { Decisiones de } \\
\text { ajustes parciales, } \\
\text { adecuación de la } \\
\text { programación del } \\
\text { taller a necesidades } \\
\text { imprevistas }\end{array}$ \\
\hline Monitoreo del taller & $\begin{array}{l}\text { - Observación } \\
\text { participante } \\
\text { - Material artístico } \\
\text { - Valoración final de } \\
\text { cada clase }\end{array}$ & $\begin{array}{l}\text { - Jóvenes } \\
\text { - Videos de registro } \\
\text { de las actividades } \\
\text { - Valoración de cada } \\
\text { clase }\end{array}$ & $\begin{array}{l}\text { ¿Cuál es la } \\
\text { percepción de las } \\
\text { actividades y del } \\
\text { taller por parte de } \\
\text { las personas } \\
\text { destinatarias? }\end{array}$ & $\begin{array}{l}\text { Decisiones de } \\
\text { ajustes parciales, } \\
\text { adecuación de la } \\
\text { programación a la } \\
\text { recepción que } \\
\text { tienen los y las } \\
\text { jóvenes }\end{array}$ \\
\hline
\end{tabular}

Fuente: Elaboración propia. 
La tercera fase corresponde, por una parte, a la recogida de datos sobre la valoración que hacen de la intervención los distintos actores implicados y, por otra parte, a la selección, categorización y análisis de toda la información recuperada a lo largo de toda la investigación. Mediante este análisis se reflexiona y valora la metodología artística empleada y el impacto que ha causado en los y las jóvenes para desvelar pistas sobre la idoneidad de la mediación artística y específicamente del teatro social como estrategia de inclusión social para trabajar con juventud migrada.

\section{Tabla 3}

Diseño de la fase III de la investigación

\begin{tabular}{|c|c|c|c|c|}
\hline $\begin{array}{l}\text { Dimensiones de } \\
\text { contenido }\end{array}$ & $\begin{array}{l}\text { ¿Cómo obtenemos } \\
\text { la información? }\end{array}$ & $\begin{array}{c}\text { ¿De quién o de } \\
\text { dónde obtenemos } \\
\text { los datos? }\end{array}$ & $\begin{array}{c}\text { Juicios a emitir } \\
\text { desde la evaluación }\end{array}$ & $\begin{array}{c}\text { Toma de decisiones } \\
\text { derivada }\end{array}$ \\
\hline Valores ciudadanos & $\begin{array}{l}\text { - Entrevistas } \\
\text { individuales } \\
\text { (virtual) } \\
\text { - Taller de } \\
\text { valoración } \\
\text { participativo } \\
\text { (virtual) } \\
\text { - Análisis de datos }\end{array}$ & $\begin{array}{l}\text { - Tallerista de teatro } \\
\text { social } \\
\text { - Coordinación del } \\
\text { programa } \\
\text { - Observadora } \\
\text { externa } \\
\text { - Jóvenes }\end{array}$ & $\begin{array}{l}\text { ¿Existe } \\
\text { participación, } \\
\text { respeto, } \\
\text { comunicación, } \\
\text { capacidad crítica y } \\
\text { de trabajo en } \\
\text { equipo entre los y } \\
\text { las jóvenes? }\end{array}$ & \multirow[t]{3}{*}{$\begin{array}{l}\text { Decisión de adaptar } \\
\text { el taller de teatro } \\
\text { social de acuerdo } \\
\text { con el conocimiento } \\
\text { generado }\end{array}$} \\
\hline $\begin{array}{l}\text { Habilidades } \\
\text { socioafectivas }\end{array}$ & $\begin{array}{l}\text { - Entrevistas } \\
\text { individuales } \\
\text { (virtual) } \\
\text { - Taller de } \\
\text { valoración } \\
\text { participativo } \\
\text { (virtual) } \\
\text { - Análisis de datos }\end{array}$ & $\begin{array}{l}\text { - Tallerista de teatro } \\
\text { social } \\
\text { - Coordinación del } \\
\text { programa } \\
\text { - Observadora } \\
\text { externa } \\
\text { - Jóvenes }\end{array}$ & $\begin{array}{l}\text { ¿Es el taller un } \\
\text { espacio de } \\
\text { confianza, de } \\
\text { creación de } \\
\text { vínculos afectivos, } \\
\text { de fomento de la } \\
\text { motivación y el } \\
\text { empoderamiento } \\
\text { identitario de los y } \\
\text { las jóvenes? }\end{array}$ & \\
\hline Metodología & $\begin{array}{l}\text { - Entrevistas } \\
\text { individuales } \\
\text { (virtual) } \\
\text { - Taller de } \\
\text { valoración } \\
\text { participativo } \\
\text { (virtual) } \\
\text { - Análisis de datos }\end{array}$ & $\begin{array}{l}\text { - Tallerista de teatro } \\
\text { social } \\
\text { - Coordinación del } \\
\text { programa } \\
\text { - Observadora } \\
\text { externa } \\
\text { - Jóvenes }\end{array}$ & $\begin{array}{l}\text { ¿Sienten comodidad } \\
\text { con los lenguajes } \\
\text { artísticos } \\
\text { propuestos? } \\
\text { ¿Existe evolución en } \\
\text { la expresividad y } \\
\text { uso de la } \\
\text { creatividad? }\end{array}$ & \\
\hline
\end{tabular}

Fuente: Elaboración propia 


\section{Resultados}

3.1. Fase I: Identificación de las personas participantes, detección de necesidades, factores de riesgo y protección y valoración de oportunidades

Mediante las distintas técnicas de recogida de información, en la primera fase de la investigación se conoce al colectivo de jóvenes y se identifican sus necesidades de inclusión social, es decir, aquellos aspectos que hace falta cubrir o desarrollar para que puedan reconocerse como parte de una sociedad y como ciudadanos y ciudadanas de un territorio, con igualdad de derechos y oportunidades.

De acuerdo con la información recogida, el $83 \%$ de los y las participantes son de origen extranjero, o bien son hijos de padres y madres migradas. Se trata de 15 jóvenes, 6 chicas y 9 chicos, entre 16 y 22 años. Cuatro corresponden a adolescentes migrados sin referentes familiares que se encuentran actualmente tutelados por la DGAIA ("Direcció General d'Atenció a la Infància i l'Adolescència”), dos son jóvenes migrados ex tutelados, seis han migrado para encontrarse con parte de su familia que ya estaba aquí, una es nacida en España, hija de madre española y padre marroquí, y dos son de nacionalidad española. Las procedencias de los y las jóvenes migradas son: Marruecos, Guinea Ecuatorial, Colombia, Honduras, Perú y Cataluña. Respecto a sus trayectorias formativas, la mayoría han completado la escolaridad obligatoria y actualmente se encuentran en situación de no estudiar ni trabajar. Por lo tanto, su principal razón para asistir al programa es tener una actividad diaria que les obligue a salir de casa, relacionarse con otras personas y recibir orientación para continuar una formación profesional.

Respecto a las necesidades de inclusión social, para comprenderlas también hace falta conocer cuáles son los factores de riesgo a los que estas personas están expuestas, es decir, aquellos aspectos de sus vidas que las hace vulnerables. Así como también los factores de protección, es decir, los aspectos que las fortalece y favorece su desarrollo. De alguna manera se busca saber lo que tienen y lo que les hace falta, así como también la valoración que hacen de aquello que sí tienen, en este caso el De Deu a Una, para diseñar un taller de teatro acorde a partir de esa información.

De acuerdo con Nin Blanco (2015), los principales factores de desigualdad que golpean a la juventud migrada son la edad, la etnia y el género, englobados por la clase social. Siguiendo este postulado, se han dispuesto estos cuatro grandes ejes de desigualdad a modo de cuatro grandes dimensiones, a partir de las cuales se desprenden distintas aristas tanto de riesgo, como de protección. Se añade la dimensión emocional, una dimensión no señalada por Nin Blanco pero que, desde la experiencia de la autora en la intervención socioeducativa y siguiendo la corriente de pensamiento de Gardner (1994) y de Romagnoli et al. (2007), es un aspecto crucial en el grado de inclusión o exclusión de una persona (ver Tabla 4 para más detalles). 
Tabla 4

Dimensiones de análisis en la fase de aproximación al contexto y diagnóstico

\begin{tabular}{|c|c|c|c|}
\hline Dimensión & Factor de riesgo & Factor de protección & Necesidades de inclusión social \\
\hline Edad & $\begin{array}{l}\text { - La calle } \\
\text { - La droga }\end{array}$ & $\begin{array}{l}\text { - Minoría de edad } \\
\text { - Hobbies } \\
\text { - De Deu a Una }\end{array}$ & - Ocupar su tiempo libre \\
\hline Etnia & $\begin{array}{l}\text { - Situación legal } \\
\text { - Discriminación }\end{array}$ & - Religión & $\begin{array}{l}\text { - Regular su situación legal } \\
\text { - No discriminación }\end{array}$ \\
\hline Género & $\begin{array}{l}\text { - Exposición a la violencia } \\
\text { de género }\end{array}$ & & $\begin{array}{l}\text { - Recibir una educación igualitaria } \\
\text { y con perspectiva de género }\end{array}$ \\
\hline Clase social & $\begin{array}{l}\text { - Pobreza } \\
\text { - Lengua } \\
\text { - Educación }\end{array}$ & $\begin{array}{l}\text { - Acceso a un móvil } \\
\text { - Hogar } \\
\text { - Inquietud por } \\
\text { formarse }\end{array}$ & $\begin{array}{l}\text { - Ingresar al mercado de trabajo } \\
\text { - Vivienda } \\
\text { - Aprender la lengua } \\
\text { - Acceso a la formación }\end{array}$ \\
\hline $\begin{array}{l}\text { Emocional } \\
\text { interpersonal }\end{array}$ & $\begin{array}{l}\text { - Falta de vínculos } \\
\text { presentes en el territorio } \\
\text { - Limitadas amistades } \\
\text { - Falta de valores de } \\
\text { ciudadanía }\end{array}$ & $\begin{array}{l}\text { - Familia } \\
\text { - Amistades }\end{array}$ & $\begin{array}{l}\text { - Afectivas } \\
\text { - Expandir sus espacios de } \\
\text { participación } \\
\text { - Desarrollar valores de ciudadanía }\end{array}$ \\
\hline $\begin{array}{l}\text { Emocional } \\
\text { intrapersonal }\end{array}$ & $\begin{array}{l}\text { - Baja motivación } \\
\text { - Baja autoestima } \\
\text { - Escasa autoconciencia }\end{array}$ & - Identidad & $\begin{array}{l}\text { Desarrollar habilidades } \\
\text { socioafectivas para la } \\
\text { construcción identitaria }\end{array}$ \\
\hline
\end{tabular}

Fuente: Elaboración propia.

\subsection{Fase II: Diseño de la intervención y productos artísticos}

A partir de las necesidades e intereses recogidos durante la fase de diagnóstico, se diseña un taller de teatro social amoldado al perfil de los y las participantes y a los requerimientos del programa. El taller se planifica para un trimestre de duración y pretende la realización de un proyecto común, al cual Ilamamos "ejercicio teatral".

Si bien todas las necesidades detectadas son consideradas a la hora de definir este taller, soy consciente de que la mediación artística como estrategia de inclusión social tiene sus posibilidades y sus limitaciones, y en sí misma no tiene la capacidad de dar respuesta a todas las necesidades identificadas y manifestadas por los y las jóvenes. Sin embargo, puede ayudar especialmente a que las personas tomen consciencia de cuáles son estas necesidades, visibilicen las opresiones que dificultan su desarrollo, crean en sí mismas y, dentro de sus posibilidades, se hagan cargo de buscar y aprovechar las oportunidades que tienen a su alcance -o en caso de que no las haya, luchar por crearlas-, para sentirse y ser consideradas ciudadanas.

De esta manera, para el diseño del taller se consideran dos necesidades de inclusión social: la necesidad de desarrollar valores de ciudadanía y la necesidad de desarrollar habilidades socioafectivas en el proceso de construcción de la identidad. Esta decisión se justifica en que la metodología artística las puede abordar y, además, porque en sí mismas engloban muchas otras. De 
aquí es que la estrategia para favorecer la inclusión social de los y las jóvenes migradas del De Deu a Una es el desarrollo de valores ciudadanos y de habilidades socioafectivas a través de la metodología del Teatro de las Oprimidas.

Como producto de la intervención artística, se crean de manera colectiva siete escenas de teatro y una pieza de rap (ver Figura 1), las cuales se basan en experiencias personales que comparten los y las jóvenes en el taller o en improvisaciones que surgen a partir de las reflexiones sobre aquellas temáticas que les atraviesan (ver Tabla 5 para más detalles). El videoclip del rap lo realiza la autora de esta investigación con imágenes grabadas durante el taller (https://youtu.be/LH4vQ-e7dZI).

\section{Tabla 5}

\section{Estructura del ejercicio escénico}

\begin{tabular}{|c|c|c|}
\hline Escena & Acción & Lenguaje \\
\hline 1 & $\begin{array}{l}\text { Cada chico y chica de forma paralela, hace una secuencia de movimiento sobre } \\
\text { cómo se sentía al momento de llegar a Barcelona o a España. Algunos llegaron al } \\
\text { aeropuerto, otros al bus, otros a la playa, etc. Los que no son inmigrantes pueden } \\
\text { hacer la secuencia de alguna persona de su familia que haya vivido una migración, } \\
\text { desde otro país o desde otra ciudad de España, o de cómo se imaginan que se } \\
\text { sentirían si emigraran a otro país. Se pueden proyectar imágenes de refugiados } \\
\text { atrás. }\end{array}$ & $\begin{array}{l}\text { Expresión } \\
\text { corporal y } \\
\text { posiblemente } \\
\text { vídeo }\end{array}$ \\
\hline 2 & $\begin{array}{l}\text { Jóvenes en plaza Cataluña compartiendo. Llega la policía y les pide } \\
\text { identificaciones, se quiere llevar a uno de ellos solo por ser extranjero. Los amigos } \\
\text { protestan. La policía se lo lleva igualmente. }\end{array}$ & Teatro \\
\hline 3 & $\begin{array}{l}\text { Un grupo de jóvenes de instituto comparten en el parque, se les acercan dos } \\
\text { jóvenes marroquíes a preguntarles algo, al escuchar que les cuesta hablar } \\
\text { castellano, los jóvenes se burlan de ellos, y luego los ignoran. Los chicos vuelven a } \\
\text { preguntar, pero ellos no quieren responder. Finalmente les piden que se vayan. }\end{array}$ & Teatro \\
\hline 4 & $\begin{array}{l}\text { Dos jóvenes sudamericanos van al ministerio de educación a preguntar los } \\
\text { trámites que debe realizar para poder estudiar en Barcelona. La o el funcionario } \\
\text { le responde que sin papeles no puede estudiar en el régimen reglado. Que se } \\
\text { puede apuntar a cursos para pasar el rato. El joven le dice que tiene sueños y } \\
\text { pretensiones de estudiar en la universidad, y que para eso necesita hacer el } \\
\text { bachillerato. Le responden de mala manera que la educación pública está } \\
\text { reservada para jóvenes españoles, no se pueden gastar los recursos públicos en } \\
\text { inmigrantes. }\end{array}$ & Teatro \\
\hline 5 & $\begin{array}{l}\text { Una chica inmigrante se junta en un bar con su jefe que la invitó después de } \\
\text { trabajar. El jefe se quiere sobrepasar con ella, por lo que ella se excusa diciendo } \\
\text { que debe levantarse temprano. Al día siguiente el jefe la está esperando, reloj en } \\
\text { mano, y la chica llega } 10 \text { minutos tarde. El jefe la despide, diciendo que es por el } \\
\text { retraso, pero todo sabemos que es porque lo rechazó la noche anterior. }\end{array}$ & Teatro \\
\hline 6 & $\begin{array}{l}2 \text { chicas llegan al De Deu a Una a preguntar si pueden acceder al programa, ya que } \\
\text { no las aceptan en ningún curso por no tener papeles. Eva les explica en qué } \\
\text { consiste y las inscribe en el grupo. Inmediatamente ellas llegan a la sala y se } \\
\text { presentan, encuentran un grupo en el cual encajan y se alegran. }\end{array}$ & Teatro \\
\hline
\end{tabular}




\begin{tabular}{|l|l|l|}
\hline Escena & \multicolumn{1}{|c|}{ Acción } & Lenguaje \\
\hline 7 & $\begin{array}{l}\text { Tres jóvenes son entrevistados en TV sobre sus sueños y expectativas. Concursan } \\
\text { por ganarse una beca para poder estudiar. Se muestra el lado B de los y las } \\
\text { jóvenes, jóvenes que tienen metas, que quieren tener oportunidades y la } \\
\text { frivolidad del sistema que los rechaza. }\end{array}$ & Teatro \\
\hline 8 & $\begin{array}{l}\text { Los y las jóvenes interpretan el Rap “Que nos den la libertad”. Atrás se proyectan } \\
\text { imágenes grabadas por ellos y ellas del barrio y sus habitantes. }\end{array}$ & Rap yídeo \\
\hline
\end{tabular}

Fuente: Elaboración propia.

\section{Figura 1}

Letra del rap

Que nos den la libertad

Que tenemos dignidad

No solo usamos drogas

También somos humanos

Asi que no critiques si

No sabes lo que hacen mis manos, eh

Vengo con mis hermanos (bis)

(Párrafo en árabe)

Libertad todos deberiamos tener

Para poder seguir siendo

Lo que queremos ser

Es un derecho que no nos lo pueden sacar

Porque lo necesitamos para poder estar

Policía, policía

Ellos cogerme un día

Sin hacer nada

Por la cara

11 horas en el calabozo

Cantando canción de Morad

Para pasar la hora

Policía, policía

Cansado

Eso se llama la vida loca

$Y$ todo lo malo

Que a mi me provoca
Me llaman buscavida

Traigo sueños y esperanza

Lo que he encontrado aqui

No es una alabanza

Soy buscavida yo

Es mi derecho

Atravieso fronteras

En busca de un nuevo lecho

Con esta sociedad

La juventud ya se aburrió

Se refugian en las redes

Y no hay oposición

Todo el mundo los critica

$Y$ nadie se pone a pensar

Que tal vez es culpa suya

Lo que acaba de pasar

Que nos den la libertad

Que tenemos dignidad

No solo usamos drogas

También somos humanos

Asi que no critiques si

No sabes lo que hacen mis manos, eh

Vengo con mis hermanos (bis)

\subsection{Fase III: Valoración del taller y análisis de resultados}

La valoración del taller se realiza a partir de la estrategia de inclusión social elegida, basada en el desarrollo de valores de ciudadanía y habilidades socioafectivas. También se opta por medir la relación de los y las jóvenes con la metodología de mediación artística, con la intención de conocer su percepción y valoración de la herramienta artística y así tener una visión más completa de su vivencia del taller. Por lo tanto, las categorías de análisis son los valores de ciudadanía -respeto, participación, diálogo, trabajo en equipo y crítica social-, las habilidades socioafectivas -cohesión grupal, motivación e identidad-y la relación de los y las jóvenes con la metodología artística. 
Para desarrollar la evaluación de la experiencia del taller, se revisan las diferentes voces que participan en este estudio, comparando y triangulando la información obtenida a partir de las distintas estrategias de investigación. La observación participante es la técnica que nos ofrece la perspectiva de la autora e interventora a partir de la interpretación que hace de las actitudes y opiniones de los y las jóvenes en el taller. A su vez, los y las participantes aportan su vivencia del taller en general y de cada dimensión evaluada en específico, a través de las entrevistas individuales y del taller de valoración participativo. La percepción de la coordinadora del programa y de la alumna en prácticas del máster de Mediación Artística recogida en las entrevistas individuales permite obtener una visión más general del taller y su metodología artística. Además, se contrasta toda esta información con la bibliografía disponible.

\section{Conclusiones}

Volviendo al objetivo de investigación, toda la información y las reflexiones aquí explicadas buscan comprender de qué manera se puede adaptar un taller de teatro social para que este favorezca el desarrollo de valores de ciudadanía y habilidades socioafectivas de jóvenes que han migrado y así recuperar la confianza de la dirección del programa en el potencial del arte como herramienta de intervención social y educativa. Tras meses de investigar, de probar diferentes estrategias y observar, de probar y errar, de preguntar a los chicos y chicas, de charlas interminables con colegas de la intervención socioeducativa, de entrar y salir del camino, de apostar y sobre todo de entregar amor y mucho compromiso a la labor socioeducativa; llego al punto de mirar hacia atrás y reconocer que todas las adaptaciones que se realizaron al taller de teatro cumplieron con sus objetivos.

Creo que, a pesar de las dificultades y de los altos y los bajos vividos durante todo el desarrollo de esta investigación que monitoreó el proceso de intervención, esta versión del taller de teatro funcionó. En primer lugar, para los y las jóvenes, porque representó aprendizajes y vivencias significativas para su desarrollo personal y su proceso de inclusión social. También resultó ser una investigación útil para el programa en cuanto al hecho de que consiguió devolver a las coordinadoras del programa la confianza en la herramienta artística, justificando para ellas la permanencia del taller de teatro social como actividad fija del recurso. En último lugar, la experiencia de haber sometido mi propia práctica profesional a observación y análisis fue tremendamente enriquecedora, ya que gané en confianza y en sustento metodológico y teórico para ofrecer experiencias socioeducativas cada vez más efectivas y dirigidas a colectivos específicos.

La inclusión social de una persona joven que ha migrado no es algo que se pueda realizar en un taller de un curso de duración. Tampoco es algo que pueda hacer la persona sola y por supuesto no es algo que pueda hacer el teatro de manera aislada. La inclusión social de una persona, como he podido comprender, es un largo camino, con diferentes aristas, que requiere del esfuerzo en red de las políticas sociales, de entidades y agentes de cambio, de la misma comunidad y sí, también de la misma persona. En este sentido entiendo las limitaciones que tiene la herramienta artística en esta misión, la mediación artística por sí sola no es la solución, el teatro de las oprimidas no puede dar respuesta a todas las necesidades de inclusión social de una persona. "El teatro es mágico, pero no hace magia" (Retuerto, 2009, p. 31). Sería iluso pensar que la marginalidad que viven adolescentes en un país donde no se les reconoce su ciudadanía, pueda ser reparada con un taller de teatro. Pero si un taller como este formara parte de toda una serie de acciones coordinadas para favorecer su inclusión social, los cambios podrían ser sustanciales. El teatro puede ayudar a que las personas tomen consciencia de cuáles son sus necesidades de inclusión social, a visibilizar las opresiones que dificultan su desarrollo, a pensar y buscar estrategias para hacerles frente, a recuperar la 
confianza en sí mismas, a desarrollar valores de convivencia, a empoderarse y dentro de sus posibilidades a que se hagan cargo de buscar y aprovechar las oportunidades que tienen a su alcance -o en caso de que no las haya, luchar por crearlas-, para "recuperar un sentido integral de la humanidad, de la condición de persona y de ciudadano" (Subirats, 2004, p. 139).

En esta investigación también me propuse identificar cuáles son las condiciones que se tienen que dar para que un taller de teatro como este se pueda llevar a cabo, se adapte a este contexto particular y signifique aprendizajes significativos para el desarrollo y la inclusión social de las personas que lo componen. Haré una revisión desde lo más estructural hasta lo más contextual.

\subsection{Voluntad política}

Al hablar de voluntad política, creo que es fundamental comenzar por denunciar una situación que da cuenta de la poca voluntad política que existe en esta materia. Cuando se interrumpieron las clases por la COVID-19, los y las jóvenes de enseñanza secundaria retomaron sus clases virtuales al cabo de pocos días, en cambio, hizo falta un mes y medio para retomar las clases del De Deu a Una de manera virtual, aun sabiendo que estos chicos y chicas son quienes más necesitan este acompañamiento socioeducativo. Esto nos parece denunciable y simplemente inaceptable. Es tiempo de dejar de tratar a estos/estas jóvenes como el último pelo de la cola, como un problema del cual los gobiernos se hacen cargo sólo si queda dinero en la caja chica. El fenómeno de las migraciones juveniles existe, es real y no se terminará por unas cuántas políticas disuasorias. Mientras la organización estructural del mundo siga dividiendo a los territorios y a las personas en el binomio dentro-fuera, estos/estas jóvenes seguirán cruzando fronteras en busca de mejores oportunidades, con la convicción de quedarse. Creo que es tiempo, pues, de hacernos cargo como sociedad de darles espacios y oportunidades de desarrollo, para que puedan formarse como ciudadanos/nas activos/as y participativos/as. La realidad es que los recursos educativos y formativos disponibles para jóvenes que han migrado sin estudios homologados y sin papeles en regla son escasos e insuficientes. Tras finalizar esta investigación, el programa De Deu a Una cerró sus puertas de manera indefinida. Esto quiere decir que uno de los pocos recursos dirigidos a jóvenes que se encuentran excluidos del sistema educativo deja de existir. Desde el Ayuntamiento de Barcelona justifican esta decisión en la apertura de la Escuela Municipal de Segundas Oportunidades, un servicio que atiende a un perfil similar de joven y que dispone de un programa más completo en tiempo y contenidos. Pero la capacidad de atención de este servicio anualmente es de 30 estudiantes, 60 jóvenes repartidos en los dos años que dura la escuela. Si se considera la cantidad de jóvenes que han migrado en estas condiciones en la ciudad es evidente que no alcanza. De esta manera, considero que la voluntad política se debe movilizar para habilitar y activar una oferta más amplia y extendida de recursos socioeducativos destinados a este colectivo, que les ayude a ocupar su tiempo, a aprender el idioma, a socializar con otros/as jóvenes, a adquirir competencias transversales y, en definitiva, a facilitar su proceso de inclusión social.

\subsection{La condición de ciudadanía}

El desarrollo de valores de ciudadanía en jóvenes es una estrategia dirigida a promover el sentido de pertenencia y la participación ciudadana, así como también destinada al desarrollo de una comunidad intercultural que comparta valores comunes. Es un instrumento para que niños, niñas y jóvenes se conviertan en personas ciudadanas activas y responsables (Bartolomé y Cabrera, 2007). 
Sin embargo, una dificultad a lo largo del taller fue lidiar con la contradicción de intentar formar ciudadanos/as cuando son personas que no tienen reconocidos sus derechos de ciudadanía. La mayoría de los/las jóvenes con quien se trabajó no tienen en regla sus papeles, lo cual de cara a la ley significa que no son ciudadanos/as. La ciudadanía se presenta entonces como un privilegio reservado solo para algunas personas. Un taller de teatro parece ser un buen lugar donde ejercitar la ciudadanía y poner en práctica los valores que la componen, pero no es suficiente. De acuerdo con Bartolomé y Cabrera (2007), debemos trabajar para construir unas "condiciones estructurales, institucionales y comunitarias que faciliten el ejercicio de la ciudadanía. Unas condiciones que animen, estimulen y reconozcan la participación e implicación de las personas en la vida, dinámicas y procesos de toma de decisión que les afectan" (p. 19). Si se pretende formar jóvenes con más conciencia de la participación en la vida política y social de su comunidad, jóvenes críticos, con capacidad de decisión, creo que es nuestro deber como sociedad darles el espacio donde puedan ejercer todas estas competencias. En cambio, se les infantiliza, se les discrimina y se les excluye de los procesos de toma de decisión en relación con asuntos que les afectan directamente. Considero pues, que los y las jóvenes que han migrado, merecen tener espacios de participación creados por y para ellos y ellas y ser considerados como interlocutores en la definición de las políticas públicas. En este sentido son especialmente interesantes los recientes nacimientos en Cataluña, en el año 2018, de dos iniciativas colectivas que pretenden reconocer la voz de este colectivo y evitar, como expresan ellos mismos, "que se hable de nosotros sin nosotros". Se trata de la Unión de Jóvenes extutelados de Cataluña (UJEC) y de la Asociación de Jóvenes EXMENAS.

\subsection{Las piedras en el zapato con las que nos acostumbramos a caminar}

La experiencia de taller de teatro social que aquí estudiamos fue realizada con adolescentes que han vivido experiencias de desprotección, de maltrato, de conflicto con la ley y de discriminación, con lo cual han sido dañados en su seguridad, autoestima y, en general, sensación de humanidad. Estas vivencias traumáticas suelen generar corazas difíciles de sobrepasar y una serie de actitudes disruptivas con las cuales el taller de teatro debió convivir. Considero importante reconocerlas, ya que representan lo cotidiano y la realidad sobre la cual se realiza la intervención teatral. Una condición para que este taller se pueda llevar a cabo es, pues, que las personas a cargo de su facilitación sean conscientes de las pautas de conducta que presentan las personas que han sufrido vivencias dolorosas, que sepan entender algunas reacciones inadecuadas de estos jóvenes sin tomárselo como una ofensa y que puedan mantener una actitud de incondicionalidad hacia los chicos y chicas. A continuación se destacan algunas de estas conductas:

- La desidia: Llegar al aula para dejarse caer inmediatamente sobre una silla, con los auriculares y el móvil en mano: "No quiero jugar profe", "Este juego no me gusta profe", "Hoy sólo quiero mirar profe", "Estoy muy cansado, profe". Comentarios de esta índole eran el pan de cada día. Existe una desgana generalizada en el colectivo de jóvenes que integran el taller. Intuyo que esta desmotivación puede tener su origen en factores como la depresión, vergüenza de exponerse frente a otros, falta de estimulación del juego y la creatividad en una etapa temprana del desarrollo, baja autoestima, o una mezcla de todas las anteriores. Sea por la razón que sea, es una realidad con la que los y las profesionales de la intervención socioeducativa debemos convivir, sin frustrarnos y sin permitir que su desmotivación se apodere de nosotras. Por el contrario, encontrando la fuerza para empujar, persuadir y estimular la participación. 
- La inconstancia: Cuando crees que tienes al grupo en la mano, uno deja de venir, otra comienza a llegar a media clase, entran unos nuevos y salen otros. La realidad en la que han crecido estos/estas jóvenes, donde la inconstancia ha estado presente de diferentes maneras, sumada a las dificultades propias de su vida actual, les dificulta comprometerse con el taller, así como con cualquier obligación que suponga asistencia y horario. De esta manera se debe crear una metodología de trabajo en la que se pueda avanzar con las personas que están, aprovechando sus potencialidades, pero donde nadie sea imprescindible, y en la que cada una de las actividades tenga sentido en si misma.

- El bloqueo creativo y expresivo: muchas personas se sienten bloqueadas en su expresividad y en su creatividad, lo que no extraña considerando que nos formamos en un sistema educativo que nos moldea de una determinada manera y que crecemos en una sociedad emocionalmente atrofiada, que no se cansa de decirnos lo que es y lo que no es aceptable. Si a esto le sumamos que hay personas a las que en su infancia no se les incentivó el juego y la creatividad, no se les reforzó su capacidad creadora, ni se les permitió expresar sus emociones, entendemos que a estas personas les resulta extremadamente difícil enfrentarse a cualquier ejercicio que implique ejercer estas capacidades. Los y las jóvenes del taller presentaban dificultades importantes en este sentido y reaccionaban o bien paralizándose y no queriendo participar, rechazando el ejercicio o recurriendo a la idea fácil y repetitiva.

- La actitud hostil: cualquier experiencia negativa o dificultosa que los chicos y las chicas trajeran de afuera, se traducía en el taller en molestia hacia la tallerista, en rechazo hacia las actividades, en agresión hacia los compañeros y compañeras y en general en una mala actitud hacia el taller y el trabajo. Entendiendo que cuando la vida te ha marginado y te ha excluido en reiteradas ocasiones, la respuesta lógica es sentir un enfado de base hacia el mundo, no resulta extraño que los y las jóvenes en ocasiones respondieran sobresaltados, faltando el respeto o incluso agrediendo a sus compañeros.

Hacer un taller de teatro con adolescentes en riesgo de exclusión social no es tarea fácil, eso ha quedado claro. Ahora revisaré aquellos aspectos metodológicos que en este taller en particular dieron resultado. No es una receta, pero es una propuesta de algunos aspectos clave para llevar adelante un proceso teatral con adolescentes que se encuentran en una situación de vulnerabilidad:

- Trabajar desde la flexibilidad y la empatía: Las planificaciones cerradas y las expectativas muy altas pueden ser enemigas de un taller de teatro en estas condiciones. Cada joven es un mundo y ha vivido experiencias que las personas profesionales a cargo no podemos ni siquiera llegar a imaginar. Por ello, propongo una metodología que se construya a partir de la escucha activa y sensible a las necesidades de cada persona. Una metodología abierta, que se constituya desde la acción, la observación y la reflexión, donde la planificación se pueda ir moldeando y adecuando a los requerimientos de las personas que forman el grupo. Para ello, es ideal si se puede establecer un tiempo de diagnóstico, tal como se ha hecho en esta intervención, en el cual se pueda medir el pulso al grupo y conocer en profundidad las necesidades y los intereses de cada persona. Para que, a partir de esta información y en consonancia con los objetivos transversales del proyecto, se puedan establecer unas metas acordes a las necesidades del grupo y crear unos indicadores de proceso para poder medir la evolución del taller. Para todo este proceso es fundamental el apoyo en las distintas técnicas y metodologías teatrales que pueden orientar la planificación de estrategias y acciones de 
cada sesión en particular y del taller en general; además las metodologías participativas tienen mucho que aportar para recoger las voces de las personas participantes.

- La creación del vínculo: Un taller de teatro es un espacio que permite a las personas entrar en contacto consigo mismas y con las demás. Que les permite jugar y vincularse desde una energía activa y reparatoria. Es un espacio que facilita la escucha integral, donde las personas aprenden a prestar atención y a ser atendidas, a ser vistas y reconocidas en su más profundo sentido de la humanidad. Las transacciones de atención y escucha que se generan en un taller de teatro son el horno de cocción ideal para que germine el vínculo, catalizando de toda una serie de procesos y aprendizajes. El vínculo es la conexión que se establece en los talleres entre las personas que componen el grupo y, a su vez, entre estas y la figura del mediador o la mediadora artística. Es fundamental que este vínculo sea positivo y que exista confianza entre las partes (Moreno, 2016). En los resultados de esta investigación se puede observar que muchas de las dimensiones analizadas dependían en gran medida del vínculo y de la cohesión grupal. Es por ello que considero que parte esencial de la estrategia de intervención socioeducativa a través del teatro debe apuntar a crear, mantener y fortalecer el vínculo entre el grupo. Para ganarse la confianza de los y las jóvenes, la persona tallerista debe tener una actitud abierta y empática, debe ser coherente y procurar generar una comunicación de horizontalidad, que otorgue a cada persona el valor que se merece, pero cuidando de establecer ciertos límites. Es importante que los y las jóvenes puedan confiar en nosotras y que dentro del espacio del taller sepan que cuentan con nuestra incondicionalidad. Pero dejando claros los límites de esa relación para no generar dependencia.

- El acompañamiento en todas las fases del proceso: Otro elemento que se revela clave al hacer un taller de teatro en este contexto, sobre todo en los primeros meses de trabajo, es el acompañamiento como eje a partir del cual articular la clase. En esta experiencia, las actividades propuestas que implicaban una gran parte de trabajo autónomo no funcionaban. Por el contrario, en los distintos momentos del taller hacía falta tirar del hilo para estimular la motivación, la participación, la comprensión y la creación. En las rondas de palabra, era común tener que estimular la opinión a través de preguntas, al trabajar improvisaciones había que romper el hielo y entrar al escenario con ellos y ellas, al construir historias había que ayudarles a indagar y profundizar, a comprender las instrucciones, etc. Hablo de adolescentes que no han tenido una continuidad formativa, que no han crecido en un ambiente de cuidado y protección y que, probablemente, han experimentado baches en su desarrollo cognitivo y psicosocial, por lo que fácilmente se pierden cuando se les pide hacer algo que se aleja de su zona de confort. Y cuando se pierden, abandonan. Este fue un aspecto que generó muchas contradicciones durante el desarrollo del taller, porque justamente la mediación artística defiende todo lo contrario. De acuerdo con Moreno (2016), el mediador o mediadora artístico/a debe tener una actitud de observación, de estar presente en el espacio, mirando, escuchando e intentando comprender lo que sucede con una actitud colaborativa. Entiendo que esta es la actitud propicia para dar espacio a que las personas profundicen en su libertad creativa y expresiva, siempre y cuando estén preparadas para hacerlo. En la realidad donde se desarrolla este taller de teatro, muchas veces las personas no saben ni por dónde empezar, por lo tanto, pretender dar una indicación y que el resto ocurra solo no es una expectativa realista. No tiene que ver con que no sean creativos, porque lo son, y mucho, pero tienen una inseguridad de base, un bloqueo emocional, una mezcla de vergüenza, miedo al rechazo y pereza, que les dificulta tremendamente poder adquirir una 
actitud proactiva hacia el trabajo. En cambio, en cuanto se produce el acompañamiento y el reforzamiento positivo es cuando se puede exprimir su real potencial. Es por lo que considero fundamental que en un taller de teatro social en un contexto como este existan dos talleristas o figuras guías, de manera que se pueda abarcar a todas las personas participantes.

- El proyecto común: Si bien, el objetivo de crear un "ejercicio teatral" fue un objetivo controvertido a lo largo del taller, que provocó sentimientos encontrados tanto en los y las jóvenes como en la tallerista, mirándolo en perspectiva, fue un pilar fundamental del proyecto. Por una parte, porque permitió mantener un rumbo a pesar de las dificultades que encontramos en el camino. Por otra parte, dio a los chicos y chicas la posibilidad de experimentar la creación estética, de ilusionarse y sentir orgullo de un trabajo bien hecho. Pese a que el objetivo de la realización del ejercicio teatral se vio frustrado por la crisis sanitaria, todo el material que alcanzamos a crear y a registrar en video se convirtió en sí mismo en el producto de nuestro taller, del cual los chicos y chicas están orgullosos porque da cuenta de lo mejor de sí y les recuerda todo lo que fueron capaces de dar. De esta manera, creo que incluso en un taller de teatro social, que no tiene como finalidad principal la creación de un producto artístico, dar a los chicos y chicas la posibilidad de transitar por el taller con la noción de que se trabaja con un objetivo común, a modo de "producto final" es una excelente manera de estimular y motivar que saquen a relucir su máxima potencialidad.

\section{Agradecimientos}

A Ferrán Cortés por guiarme en este proceso investigativo; a Marta Sabariego por su generosidad metodológica; a Eva de la Flor por su disposición, compromiso educativo y amor por los y las jóvenes del programa; a Elena por ser los ojos que yo no podía ser; a Abdel, Abdou, Abigail, Ana María, Cristian, Fabiola, Gabriel, Haffed, Ian, Johan, Juan Carlos, Mafe, Mar, Mohamed, Oussama, Rochdi, y Yasmin, y a todos los y las jóvenes que cruzan fronteras buscando una vida mejor.

\section{Referencias}

Bartolomé, M., y Cabrera, F. (2007). Construcción de una ciudadanía intercultural y responsable. Narcea Ediciones.

Boal, A. (1980). Teatro del oprimido: Teoría y práctica. Editorial Nueva Imagen.

Castel, R. (1995). De la exclusión como estado a la vulnerabilidad como proceso. Archipiélago, 21. http://www.dwvalencia.com/claver/Documentos/exclusion(robert_castel).pdf

Gardner, H. (1994). Educación artística y desarrollo humano. Paidós Ibérica.

Gimeno, Ch. (2014). Buscavidas. La globalización de las migraciones juveniles. Universidad de Zaragoza.

Moreno, A. (2016). La mediación artística: arte para la transformación social, la inclusión social y el desarrollo comunitario. Ediciones Octaedro. 
Nin Blanco, R. (2015). Jóvenes, migraciones y exclusión social. Miradas y dispositivos para la intervención social en el ámbito catalán [Tesis doctoral, Universidad Nacional de Educación a Distancia]. http://e-spacio.uned.es/fez/eserv/tesisuned:Filosofia-

Rnin/NIN_BLANCO_Maria_del_Roser_Tesis.pdf

Retuerto, I. (2009). Una Tortuga, una Escalera. Metodología de teatro reparatorio con niñas, niños y adolescentes vulnerados en sus derechos. ONG Raíces.

Romagnoli, C., Mena, I., y Valdés, A. M. (2007). ¿Qué son las habilidades socio afectivas y éticas? Documentos Educarchile. http://valoras.uc.cl/images/centrorecursos/equipo/ValoresEticaYDesarrolloSocioemocional/Documentos/Que-son-las-habilidadessocioafectivas-y-eticas.pdf

Serracant, P. (coord.) (2013). Enquesta a la joventut de Catalunya 2012. Les diferents vivències de la joventut. Departament de Benestar Social i Família. http://ejoventut.gencat.cat/web/.content/observatori_catala_de_la_joventut/documents/arxiu/p ublicacions/coleccio_estudis/ejc_volum2_publicacio_completa.pdf

Subirats, J. (dir.) (2004). Pobreza y exclusión social. Un análisis de la realidad española y europea. Fundación La Caixa. https://fundacionlacaixa.org/documents/10280/240906/vol16_es.pdf

Subirats, J., Alfama, E., y Obradors, A. (2009). Ciudadanía e inclusión social frente a las inseguridades contemporáneas. La significación del empleo. Documentos de Trabajo (Fundación Carolina), 32, 133-142. https://dialnet.unirioja.es/servlet/articulo?codigo $=3049450$ 